\title{
The application of transpersonal and spiritual care for older adults receiving palliative care
}

Johnata da Cruz Matos' $\mathbb{1 D}$ Silvia Maria Ferreira Guimarães' ${ }^{1}$

\section{Abstract}

Objective: To identify the perception of nurses regarding spiritual care for older patients undergoing palliative care. Methods: A descriptive study with a qualitative approach was carried out with 27 care nurses at the Hospital Universitário de Brasília, Brazil, in 2018. The interviews were conducted through a semi-structured script and submitted to content analysis. The discourse structuring for the collective subject technique was applied. Results: Five discourses of the collective subject were constructed and grouped into two categories entitled Spiritual Care Provided By Nurses, and Favorable and Unfavorable Factors For the Provision of Spiritual Care For Older Patients. From the central nuclei contained in the reports, the respondents considered spiritual care and family participation in palliative care important. However, they mainly attributed the role of intervening in spirituality to religious volunteers and the family. Conclusion: The study shows that despite the difficulties in providing spiritual care, family support, moments of listening and the carrying out of activities that motivate inner peace are significant for an improved response to the spirituality of older patients.

Universidade de Brasília (UnB), Faculdade de Ceilância, Programa de pós-graduação em Ciências e Tecnologias em Saúde. Brasília, DF, Brasil.

The authors declare there are no conflicts of interest in relation to the present study.

No funding was received in relation to the present study.

Keywords: Nursing Care. Palliative Care. Spirituality. Health of the elderly. 


\section{INTRODUCTION}

Aging is a natural process and represents a stage of human life. Technological advances have brought about a reduction in mortality rates resulting from improved sanitary conditions and a decrease in fertility rates due to birth control, meaning the age pyramid in Brazil continues to undergo a process of inversion, causing increased population aging. However, aging is also one of the risk factors for the development of chronic diseases, including cancer ${ }^{1}$.

The development of the ability to think rationally and logically resulted in a need to try to understand the meaning of life and death, especially for individuals who had exhausted the therapeutic possibilities of a cure, and who required different care from those who seek healing treatment ${ }^{1}$.

Palliative care is a modality of care granted to the patient and their family when faced with a disease or clinical condition that threatens the continuity of life. These interventions are provided by a multidisciplinary team that observe the patient in their physical, social, psychological and spiritual aspects, with the purpose of improving the quality of life, carrying out the prevention and identification of diseases, as well as relieving suffering and pain, permeated by effective communication. In this sense, this new approach is essential when clinical and therapeutic healing interventions are no longer effective ${ }^{2}$.

In 2015, Brazil ranked $42^{\text {nd }}$ in the Quality of Death Index, which evaluated the palliative care provided by eighty countries through the analysis of reports from health professionals, the existence of national policies and investments aimed at palliative care $^{3}$. Despite Brazil's growth in relation to previous editions of the index (2009 to 2014), and the existence of legislation that ensures citizens' right of access to this type of therapy, the country continues to have difficulties in implementing quality of care ${ }^{4}$.

While for many the terms spirituality and religiosity have the same meaning, they are in fact different processes. Spirituality corresponds to a unique knowledge of each individual that seeks explanations that go beyond their understanding of the existential process. It has an essential role in the process of care and treatment of diseases, as it is not based exclusively on religion, but on principles linked to its own values, and can thus be included in the various stages and contexts ${ }^{1,5,6}$.

In contrast, religiosity refers to a practice based on belief and bringing the believer closer to specific deities. In this sense, religious activities govern a collective behavior and way of life that can be shared between people of the same religion ${ }^{1,5,6}$.

The theorist Jean Watson became a reference within the nursing practice, as during her professional experiences she attributed a new meaning to care practice, advocating an approach that would allow her to go beyond scientific knowledge and consider humanistic aspects to meet the needs of the patient, family and community. Therefore, the Theory of Transpersonal Caring is defined as a framework that contemplates care in different scenarios and with greater interaction between the health professional and the patient ${ }^{7,8}$.

Transpersonal Caring advocates the promotion of a spiritual approach in the care process. Nursing should not be based on the traditional biomedical model, which focuses only on curing diseases through a series of established protocols, but identifies spirituality as an important aspect in the patient's comprehensive care. In addition to including a spiritual dimension in care, Watson explains that through the nurse's interaction with the patient, it is possible to explore the emotions and subjectivity of both and analyze their relationship in the care process?

Palliative care has become increasingly present in nursing interventions for older patients. It is therefore necessary to understand the perception of nurses regarding the importance and meaning that spirituality has in care. Since these professionals spend more time with patients and family members during hospitalization, they often perceive their particularities more easily. In this sense, apprehending their perception is essential to broaden debates on this topic.

In the face of so many challenges involving the spiritual dimension in palliative care, the present study is based on the following guiding question: How do 
nurses perceive the importance of spiritual care for older patients in palliative care? The study therefore aims to understand the perception of nurses about spiritual care for older patients in palliative care.

\section{METHOD}

A descriptive study with a qualitative approach was carried out. To better understand the thoughts of the subject, group or collective unit, one should explore their ideas through qualitative knowledge, which aims to assess quality subjectively ${ }^{10}$.

The study involved 27 care nurses from the Hospital Universitário de Brasília (HUB) in the period from July to November, 2018. The inclusion criterion was nurses who had worked in the Medical Clinical sector of the HUB for a minimum period of one year, with this time established to ensure that these professionals had sufficient experience with palliative care to achieve the research objectives. The exclusion criteria were nurses who were on vacation or leave during the period of data collection, as well as those who did not perform care activities, that is, who only worked in administrative roles.

Subsequently, the data were collected through an interview conducted with a semi-structured script, audio recorded in a private location, confirming the right of the participants to data confidentiality.

The interviews were transcribed in their entirety and analyzed using the content analysis technique, where ideas are described as a union of different methodologies which have the function of examining various forms of arguments, with the purpose of observing all the data obtained, whether verbal or non-verbal ${ }^{11}$. The textual corpus was submitted to the content analysis technique. Through the analysis of extracts from the discourse of the participants, it was possible to identify the central nuclei found in the reports, and this allowed the formation of the DCS. In this sense, priority was given to the main approaches and meanings of spiritual care and organized to carry out the application of Jean Watson's Theory of Transpersonal Caring.

The technique of structuring the Discourse of the Collective Subject (DCS) brings together social representations, linking individual interpretations with collective perspectives, that is, it groups together particular ideas with a similar logic, to build a discourse that expresses the concept of the collective point of $\mathrm{view}^{12}$. There is no individual identification of the research participants, as the statements present a collective idea. The ethical recommendations were met, and the research was approved by the Ethics and Research Committee of the Faculdade de Ceilândia (the University of Ceilândia) (FCE), of the Universidade de Brasília, under decision number 2.642.997 on 08/03/2018.

\section{RESULTS}

The studied sample consisted of 27 nurses who work in direct palliative care for older adults with no possibility of cure, as described in Table 1.

Of the participants, $74 \%$ were female. When asked how much nursing training they had, $37 \%$ had fewer than five years, $37 \%$ had five to ten years, and $26 \%$ had more than ten years of training.

Regarding the length of experience with palliative care, all participants had less than five years and $51.5 \%$ reported having completed at least one training program focused on the topic of palliative care and terminality of life.

The technique of content analysis and the structuring of the discourse of the collective subject allowed two categories to be distinguished, entitled Spiritual Care Provided By Nurses, and Favorable and Unfavorable Factors For the Provision of Spiritual Care. 
Table 1. Distribution of the sociodemographic characteristics of the participants. Brasília, Distrito Federal, 2019.

\begin{tabular}{ll}
\hline Analyzed variable & $\mathrm{N}(\%)$ \\
\hline Sex & $20(74 \%)$ \\
Female & $07(26 \%)$ \\
Male & $10(37 \%)$ \\
\hline Years of nursing training & $10(37 \%)$ \\
Fewer than 5 & $07(26 \%)$ \\
From 5 to 10 & \\
More than 10 & $27(100 \%)$ \\
\hline Years of experience with palliative care & - \\
Fewer than 5 & \\
From 5 to 10 & $13(51.5 \%)$ \\
Participation in training courses & $14(48.5 \%)$ \\
Did not participate & \\
Participated in training & \\
\hline
\end{tabular}

\section{Spiritual Care Provided By Nurses}

When faced with nursing care based on biomedical models and focused only on curing the disease, an approach that values the patient fully is required, treating each individual according to their specificities and diverse needs, as noted in DCS 1.

Care is not just about providing nursing care. All of this involves psychological, spiritual, religious aspects, because everyone is different, everyone has their own beliefs. We have to know how to respect the opinion of the individual. The spiritual part is very important. Knowing that we don't take anything with us from this life. So, we work with pain control, psychological work, comfort, in general, so that the patient even improves during the stage of accepting their own death, especially older patients. However, more important than the technique, than the technical procedures, I think, is this more humanistic approach, to see the patient as a being, who thinks, with needs, who has their religion, who has their beliefs, their values.

From this discourse, it can be seen that the participants believe that addressing spiritual aspects improves the acceptance of older patients in palliative care in the process of the finitude of life.
In addition to ensuring the opinions of individuals and maintaining respect for their religious beliefs, nursing professionals place pain relief as a priority.

Due to the large number of patients, the overburden of work and the excess of technical procedures, the care team is limited to promoting care focused on the biological aspect, relegating care in the other dimensions to a secondary level and not providing adequate spiritual support to the patient, the family and the nursing team itself.

In DCS 2, it can be seen that most participants delegate the function of providing spiritual care to other professional classes, religious entities and even family members.

In reality, it's not our job, is it? There is work with psychosocial and spiritual aspects, but as in the hospital, nurses are more involved than any other health professional, we try a bit. But care focused on spirituality offered by nursing on a continuous basis doesn't happen. There are also visits, because this is a hospital open to all beliefs and religions and creeds, so each creed, belief, has its spiritual support. So, the spiritual part is mostly up to the volunteers. We promote listening and are more focused on prescription. It is what is written there, it's care. As at some points the patient just wants 
a word of comfort, a friendly word and, due to our routine, we are sometimes unable to do this. Then, sometimes, the family also takes on this very important role.

According to the discourse, representatives of different religions provide spiritual support, and according to the participants, mistakenly, this function is not seen as attributed to nursing professionals.

The presence of contradictory concepts can be perceived and this shows us that the participants confuse the meaning of spirituality with religiosity, which may impair the choices of interventions to be provided during spiritual care, as religion provides only part of the spiritual dimension.

The participants, despite attributing the spiritual approach to religious volunteers, promote and stimulate therapeutic listening, which is one of the main methods used in spiritual care. In this sense, the participating nurses do not realize that this is a therapeutic action in the care process.

DCS 3 shows the importance of including the family in the care process. A family educated about conduct within palliative care can act as an aid to the team. However, an uninformed and non-participative family assumes the role of subject to be cared for by the patient.

If the family does not participate, the patient feels rejected, feels angrier, often they have accepted that there is no point in care and that they are really going to die, so if they realize that the family is there more, they accept it more easily because they know that they're there and they are being cared for, so there is still a prospect of improvement, they might still go home. So, all this has an effect. The family is an antidepressant, the family is often better than medicine. The medication eases their pain, internal pain, the pain suffered, but only the family works for the mind. The approach of the family is essential. So, family is not only a wife, children and grandchildren, you know? Family is who the patient considers family, be it a friend, a companion, a cousin, a neighbor or even a pet. I think the participation of someone $\mathrm{n}$ is very important. Nobody wants to die alone, do they?
In care, the importance of the family is wellknown, as patients accompanied by their families have a more positive response during the treatment provided, that is, it is not only medication that relieves pain and discomfort, but the support of relatives. On the other hand, those who remain alone, in addition to feeling abandoned, do not express an expectation of progress or improvement of symptoms.

It is possible to observe the benefits if the team includes family members in the process; however, it is important to highlight that nursing professionals must respect the patient's opinion of who makes up their family.

\section{Favorable and Unfavorable Factors For the Provision of Spiritual Care to Older Patients}

It can be seen that in DCS 4 that, when nursing professionals act in a cohesive manner that is focused on the needs of the patient and their family, care becomes more effective and patients experience humanized care.

\begin{abstract}
What makes it easier? It really is the team, because here the team is really united, organized, we see this commitment, with the patients. The team here is very human. It is important to try to respect the autonomy of the patient. The older patient wants an activity to distract themselves, a painting, a craft or something they have always done at home, we can detect this wish, and if they're able, we offer the activity. We had a patient that painted. She had been a teacher and did several drawings during the day and she gave it to the other patients. So, we put it on the headboard and it was really cool. She felt good about painting. She let us know that she was satisfied. When she was doing this the whole team was involved, encouraging her.
\end{abstract}

It can be seen that interventions can evolve and go beyond a simple conversation, thus giving a new meaning to spiritual care, easing the anxieties of the patient and allowing an improvement in the quality of life. When the team is united and communication flows effectively between professionals, even the simplest practices result in a diversified and individualized approach. 
Based on the discourse, the promotion of activities that stimulate happiness, pleasure and satisfaction, alleviate the disabilities that older patients experience during hospitalization. These dynamics allow the growing desire to live and the search for feelings of usefulness and functionality during palliative care.

In DCS 5, it can be inferred that the nursing professionals do not feel prepared to provide spiritual support, describing obstacles such as a lack of time due to the demands of the hospital, not having a private environment for such care, the difficulty of talking about issues religious beliefs, the patient's lack of confidence in the nursing professional, and also because they do not have adequate knowledge or training.

And you have to have training too, right? I think this is essential because, sometimes, we do not know how to deal with the patient, how to deal with the family. The family member can be very unstable, because for them, maybe it's not well explained or they don't accept the condition of the patient. They are very shaken up. Even though they know it's palliative, they want them to carry out often unnecessary interventions, up to the last moment. There is also the issue of work overburden, which I consider to be the main factor that makes it difficult. Sometimes, you want to provide good care, but due to the large number of patients, you can't provide it as you would like. Nobody accepts death, it makes it very difficult. Today, the professional training for everyone is to take care of those who will survive. You leave college thinking that you are going to save lives. It's pretty complicated. Another thing that I think is difficult is the lack of communication, the lack of dialogue between different professions. I almost can't, for example, talk to the psychologist or the doctor. This is a problem.

During the interview the nurses clarify that the family can interfere with care by not understanding the patient's health status. Therefore, nursing professionals must be able to provide spiritual care for this group, in the context of restrictions such as mourning, the constant search for life and interference in the care provided by the team.

\section{DISCUSSION}

The analysis of the duality between life and death and the clear perception of the proximity of the end of life, results in the emergence of varied, often conflicting, feelings, such as anxiety, grief, fear, peace and acceptance, all perceived in the search and experience of spirituality. Each patient who undergoes palliative care perceives this moment of great complexity in a unique and personal way ${ }^{13}$.

Difficulty in dealing with death, attachment to the constant struggle to maintain life, fear and the search for the prevention and relief of pain and suffering are significant aspects in the lives of older patients who are in vulnerable conditions. It is important for patients at this time to highlight feelings such as the relevance of faith and the meaning of life, which can contribute to the relief of various symptoms ${ }^{14}$.

The Theory of Transpersonal Caring applies the faith-hope stimulus and correlates it with nursing care to promote patient stability. By respecting the beliefs and limitations of each patient, transpersonal caring is guided beyond human needs and the health recovery process. The inclusion of spiritual care is essential in palliative care, given that family support, love, hope and faith are fundamental characteristics to meet the needs of clients during team interventions ${ }^{8}$.

A large part of health practices are still limited in terms of the care of the spiritual dimension. Often due to the lack of skills and abilities of professionals, taking care of aspects that involve body, mind and spirit, remains a great challenge. Thus, it is important to understand the importance of integral care in order to overcome paradigms that can have repercussions on therapy and the entire care process ${ }^{3}$.

When considering the assumptions of Transpersonal Human Caring, Jean Watson describes the need to promote incentives that include integral care for families. Thus, such conditions should always permeate spiritual care both for the older patient during the terminal life process, and for the family until the end of the grieving period ${ }^{15}$. 
The family is one of the most important sources of support for older patients in palliative interventions. It enables and facilitates spiritual care by allowing the team access to the patient's life stories, their beliefs, expectations and reluctances. In this sense, it is up to nursing professionals to promote the inclusion of people who represent an affective bond for the patient, in order to assist in the assistance and contribute to the nurse's performance. These relatives and friends also suffer through the patient's illness and it is the team's role to welcome and mitigate the suffering of all involved ${ }^{16,17}$.

One of the central axes presented by the theory of Transpersonal Human Caring, consists of the development of a relationship of help and trust that enriches the individual growth of the nurse and the patient, guaranteeing a relationship without therapeutic impasses which allows the new goals in the care process to be established ${ }^{15,18}$.

The performance of nursing professionals in teamwork allows the provision of humanized care to patients and their families. A spiritual approach is not limited to theories and protocols, and it is necessary to promote moments of listening, paying attention to the patient's preferences and providing moments that value their comfort and well-being ${ }^{14}$.

It is important to analyze how the treatment of older patients in palliative care is still an obstacle for nursing. In order to build a transpersonal relationship, it is necessary for nurses to disconnect from previously determined principles, and be willing to become involved in comprehensive care. This means that emotional involvement with the patient is essential ${ }^{9,14}$.

The process of the finitude of life stimulates several emotional reactions, involving the nursing professional, the patient and the family, as it forces everyone to analyze their finitude. Proposing to the nursing team that their performance can be humanized even in the face of so many vulnerabilities is complex as the academic training of many professionals instructs them to always prioritize the protection and preservation of life, thus leaving them unprepared to deal with death ${ }^{14}$.
Due to the difficulty of nurses in addressing spiritual care and the lack of preparation and insertion of this practice in the routine of the nursing team, it is crucial to encourage research on this subject, to work in tandem with care and add new knowledge about palliative care and spirituality.

On a similar note, the limited amount of literature on spirituality and the lack of knowledge of the participants regarding spiritual care were the main factors that limited the research.

\section{CONCLUSION}

The results obtained allow us to understand the perception of nurses on spiritual care in the palliative care process. It was also possible to analyze the perspective of nurses on the meaning and importance of spiritual care in the palliative phase through an integral approach, which is essential to developing practices that in addition to encouraging faith and spirituality, perseverance and expectations about the end of life, allows glimpses of the different aspects of human existence.

The biggest challenge for the research participants was to see that spiritual dimensions should have greater relevance in the daily life of those who provide care and are cared for. Sometimes, what hindered spiritual assistance was the lack of knowledge about concepts such as religiosity and spirituality, the demands of an exhaustive work routine, care centered on the physical-biological aspects, the lack of time for a spiritual approach, the absence of emotional support for the team and even a fragmented professional training that contributed little to the insertion of this practice in palliative care.

Throughout the development of the study, it was seen that family support, moments of listening and the execution of activities that motivate inner peace are significant for nurses. However, dealing with the spirituality of the patient in palliative care reveals aspects that go beyond the care perspective, which is currently focused mainly on pain relief and the promotion of comfort. In view of this, it 
is essential for the entire care team to look at the patient holistically, treating the human being in its biopsychosocial and spiritual dimensions.

Thus, a new research proposal on this topic could involve the understanding of other professionals from the multidisciplinary team, in addition to covering other hospital sectors involved in the process, to add and optimize spiritual care in all dimensions of care and identify coping strategies in other contexts.

Edited by: Tamires Carneiro Oliveira Mendes

\section{REFERENCES}

1. Cervelin AF, Kruse MHL. Spirituality and religiosity in palliative care: learning to govern. Esc Anna Nery Rev Enferm. 2014;18(1):136-42.

2. Morais E, Conrad D, Mattos E, Cruz S, Machado G, Abreu M. Palliative care: coping nurses in a private hospital in the city of Rio de Janeiro - RJ. Rev Pesqui Cuid Fundam. 2018;10(2):318-25.

3. Kelly D. Politics and palliative nursing. Int J Palliat Nurs. 2018;24(1):3-8

4. Luiz MM, Netto JJM, Vasconcelos AKB, Brito MCC. Palliative nursing care in the elderly in UCI: an integrative review. Rev Pesqui Cuid Fundam. 2018;10(2):585-92.

5. Gomes NS, Farina M, Forno CD. Spirituality, religion and religion: concepts reflection in psychological articles. Rev Psicol IMED. 2014;6(2):107-12.

6. Arrieira ICD, Thofehrn MB, Milbrath VM, Schwonke CRGB, Cardoso DH, Fripp JC. The meaning of spirituality in the transience of life. Esc Anna Nery Rev Enferm. 2017;21(1):e20170012 [6 p.].

7. Tonin L, Nascimento JD, Lacerda MR, Favero L, Gomes IM, Denipote AGM. Guide to deliver the elements of the Clinical Caritas Process. Esc Anna Nery Rev Enferm. 2017;21(4):e20170034 [7 p.].

8. Savieto RM, Leão ER. Nursing assistance and Jean Watson: a reflection on empathy. Esc Anna Nery Rev Enferm. 2016;20(1):198-202.

9. Santos KH. Nursing care in people with sickle cell anemia: application of Jean Watson's theory in the nurse-individual relationship. Saúde rev. 2016;16(44):55-61.

10. Wadams M, Park T. Qualitative research in correctional settings: researcher bias, west ern ideological influences, and social justice. J Forensic Nurs. 2018;14(2):72-9.

11. Carlomagno MC, Rocha LC. Como criar e classificar categorias para fazer análise de conteúdo: uma questão metodológica. Rev Eletr Ciênc Política. 2016;7(1):173-88.

12. Lefevre F, Lefevre AMC. Discourse of the collective subject: social representations and communication interventions. Texto \& Context Enferm. 2014;23(2):502-07.

13. Benites AC, Neme CMB, Santos MA. Significance of spirituality for patients with cancer receiving palliative care. Estud Psicol. 2017;34(2):269-79.

14. Evangelista CB, Lopes MEL, Costa SFG, Abrão FMS. Spirituality in patient care under palliative care: a study with nurses. Esc Anna Nery Rev Enferm. 2016;20(1):176-82.

15. Guerrero-Ramírez R, Meneses-La Riva ME, de La Cruz-Ruiz M. Humanized care of nursing according to the theory of Jean Watson, medical service of the hospital Daniel Alcides Carrión. Rev Enferm Herediana. 2016;9(2):133-42.

16. Lima MP, Oliveira MC. Meanings of nursing care for the family of patients in palliative care. Rev Rene. 2015;16(4):593-602.

17. Matos JC, Borges MS. The family as a member of palliative care assistance. J Nurs UFPE online. 2018;12(9):680-85.

18. Izquierdo ME. Enfermería: teoría de Jean Watson y la inteligencia emocional, una visión humana. Rev Cuba Enferm. 2015;31(3):1-11. 